\title{
Analysis of morphine responses in mice reveals a QTL on
}

\section{Chromosome 7 [version 1; peer review: 2 approved]}

\author{
Wim E. Crusio (D1,2, Esha Dhawan ${ }^{3,4}$, Elissa J. Chesler5, Anna Delprato (iD 4 \\ ${ }^{1}$ Institut de Neurosciences Cognitives et Intégratives d'Aquitaine, UMR 5287, University of Bordeaux, Pessac cedex, France \\ ${ }^{2}$ Institut de Neurosciences Cognitives et Intégratives d'Aquitaine, UMR 5287, CNRS, Pessac, France \\ ${ }^{3}$ Lambert High School, Suwanee, USA \\ ${ }^{4}$ BioScience Project, Wakefield, USA \\ 5Jackson Laboratory, Bar Harbor, USA
}

V1 First published: 02 Sep 2016, 5:2156

https://doi.org/10.12688/f1000research.9484.1

Latest published: 27 Oct 2016, 5:2156

https://doi.org/10.12688/f1000research.9484.2

\section{Abstract}

In this study we identified a quantitative trait locus (QTL) on mouse Chromosome 7 associated with locomotor activity and rearing post morphine treatment. This QTL was revealed after correcting for the effects of another QTL peak on Chromosome 10 using composite interval mapping. The positional candidate genes are Syt9 and Ppfibp2. Several other genes within the interval are linked to neural processes, locomotor activity, and the defensive response to harmful stimuli.

\section{Keywords}

Opioids , QTL analysis , Locomotor activity , Reward pathway

\section{‘incf}

This article is included in the INCF gateway.

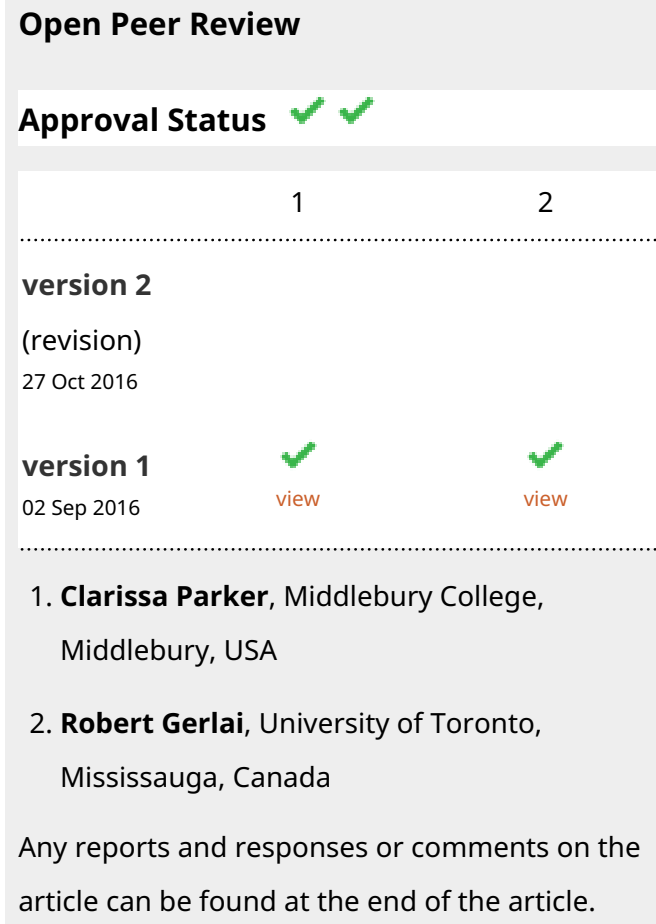

1. Clarissa Parker, Middlebury College, Middlebury, USA

2. Robert Gerlai, University of Toronto, Mississauga, Canada

Any reports and responses or comments on the article can be found at the end of the article.

Corresponding authors: Elissa J. Chesler (Elissa.Chesler@jax.org), Anna Delprato (annadelprato@gmail.com)

Competing interests: No competing interests were disclosed.

Grant information: BioScience Project is a 501(c)(3) research and teaching organization. EJC was supported by grants from NIAAA (AA018776) for GeneWeaver and NIDA (DA037927) for addiction genetics.

The funders had no role in study design, data collection and analysis, decision to publish, or preparation of the manuscript.

Copyright: (c) 2016 Crusio WE et al. This is an open access article distributed under the terms of the Creative Commons Attribution License, which permits unrestricted use, distribution, and reproduction in any medium, provided the original work is properly cited.

How to cite this article: Crusio WE, Dhawan E, Chesler EJ and Delprato A. Analysis of morphine responses in mice reveals a QTL on Chromosome 7 [version 1; peer review: 2 approved] F1000Research 2016, 5:2156 https://doi.org/10.12688/f1000research.9484.1

First published: 02 Sep 2016, 5:2156 https://doi.org/10.12688/f1000research.9484.1 


\section{Introduction}

Responses to drugs of abuse vary among individuals and are genetically influenced (Mistry et al., 2014). Such drugs stimulate the brain reward pathway (Gardner, 2011). Analysis of genetic variation in the behavioral and neurobiological processes can reveal molecular mechanisms that regulate or mediate the response to drugs, and neurobiological changes associated with chronic drug use. Many of the genes and signaling processes involved in the reward pathway in humans are conserved in mice (Adinoff, 2004), and mouse genetic methods provide an efficient means of identifying these genes and loci.

Quantitative trait loci (QTL) analysis of recombinant inbred mouse strains (RIS) integrates phenotype and genotype data and is a widely used approach for studying the genetic basis of drug effects and addiction susceptibility (Spence et al., 2005). The BXD RIS, derived from C57BL/6J (B) and DBA/2J (D), are a wellestablished genetic reference population used in behavioral neuroscience studies for mapping complex traits associated with drug use (Crabbe et al., 1996; Dickson et al., 2016; Gora-Maslak et al., 1991; Peirce et al., 2004; Plomin et al., 1991).

In the present study we reanalyzed data from high throughput behavioral phenotyping of BXD RIS in the presence of morphine (Philip et al., 2010). Our purpose was to identify additional morphine response related genetic loci beyond those initially reported. We employed composite interval mapping for two behavioral phenotypes, rearing and locomotion in response to morphine, and identified a QTL on mouse Chromosome 7 that was masked by a major QTL on Chromosome 10.

\section{Methods}

Experimental protocols have been described elsewhere (Philip et al., 2010). BXD data were generated in the laboratory of Dr. Charles D. Blaha at the University of Memphis and obtained from GeneNetwork.org.

\section{QTL mapping}

QTL mapping was performed using GeneNetwork 1.0 with a composite interval mapping function using 2000 permutations. This is a forward regression approach in which a single locus with a major effect is included in a mapping model that scans for additional additive effects and interactions with the major locus. The technique will miss higher order interactions among loci that are not detectable as main effects, but is effective when a large, consistently observed major effect locus is present. Strain mean scores were Winsorized when statistical outliers were present. We first determined which marker had the highest LRS value, using a marker regression analysis and then performed composite interval mapping, controlling for the Chromosome 10 SNP rs3721803, one of the 3 markers with the highest LRS scores.

\section{Bioinformatics}

The MGI database (http://www.informatics.jax.org/) was used to find information about SNPs and strain polymorphisms occurring within the Chromosome 7 interval (queried -June 20, 2016). This database now includes variants detected in the sequencing of 17 mouse genomes (Keane et al., 2011). The 3 SNPs located at the Chromosome 7 QTL peak (rs13479451, rs3724540, rs6386601) are at $\sim 114.5 \mathrm{Mb}$ in GeneNetwork and $\sim 107.6 \mathrm{Mb}$ in the MGI and NCBI databases (http://www.ncbi.nlm.nih.gov/gene). In GeneNetwork, the relevant QTL interval on Chromosome 7 was $110-125 \mathrm{Mb}$ whereas this region corresponds to $103-118 \mathrm{Mb}$ in the MGI database. As finer mapping methods are developed, the exact interval location as reported here, may change. DAVID version 6.8 (https://david.ncifcrf.gov/) was used to obtain functional annotations and pathway information for the genes within the interval and GeneWeaver 1.0 (http://www.geneweaver.org/) to identify other drug-related phenotypes associated with the candidate genes.

\section{Results}

Composite interval mapping

As reported by Philip et al. (2010), whole genome scans produce robust QTLs mapping to Chromosome 10 at $0-30 \mathrm{Mb}$ (Figure 1A-B). The positional and functional best gene candidate is the Oprml gene which encodes the opioid G-protein coupled receptor mu 1 (Philip et al., 2010) which has been previously detected (Bergeson et al., 2001; Doyle et al., 2014).

We remapped these data for each time point using composite interval mapping to identify QTLs potentially masked by this large QTL. This revealed a second significant QTL on Chromosome 7 for locomotion $(\mathrm{LRS}=18.0,114.7 \mathrm{Mb}$; Figure 1C) and, in an overlapping position, for rearing ( $\mathrm{LRS}=16.5,114.3 \mathrm{Mb}$ ). We also observed a time dependent decrease of the peak LRS values for both traits after the 60-75 minute time interval post-morphine injection. A suggestive QTL for the rearing trait data was already apparent on Chromosome 7 from the whole genome scan, but this was not the case for the locomotion trait data (Philip et al., 2010).

The area under the QTL peak contains 280 protein coding genes (MGI Chromosome 7: 103-118 Mb, GeneNetwork Chromosome 7: 110-125 Mb; database query-June 20, 2016, Supplementary worksheet 2). Of these genes, 162 are associated with olfactory receptors. Of the other genes with functional annotations, 11 are connected with neural processes (Adm: neural tube development, Appb1, Tub, Calca, Cckbr, Cnag4: sensory perception and cognition, Insc, Arntl: neurogenesis, Tpp1: neuromuscular control, Rras2: regulation of neuron death and $P d e 3 b$ : morphine addiction (KEGG pathway 05032).

There are 3 SNPs mapped at the location of the LRS peak and two positional candidates: Synaptogamin 9 (Syt9: rs13479451, rs3724540) and PPFIA binding protein 2 (Ppfibp2, rs6386601). Both of these genes differ between the parental strains (MGI database query - June 20, 2016). Syt9 functions in vesicle traffic and $\mathrm{Ca} 2+$ triggered exocytosis (Ncbi, 2016b) and Ppfibp2 is involved in the regulation and development of neuronal synapses (Ncbi, 2016a). These two candidates are also differentially expressed in the striatum of the brains of mice from strains with distinct opioid sensitivity (Korostynski et al., 2006; GeneWeaver: Syt 9, geneset \#86830; Ppfibp2, geneset \#86906). 
A

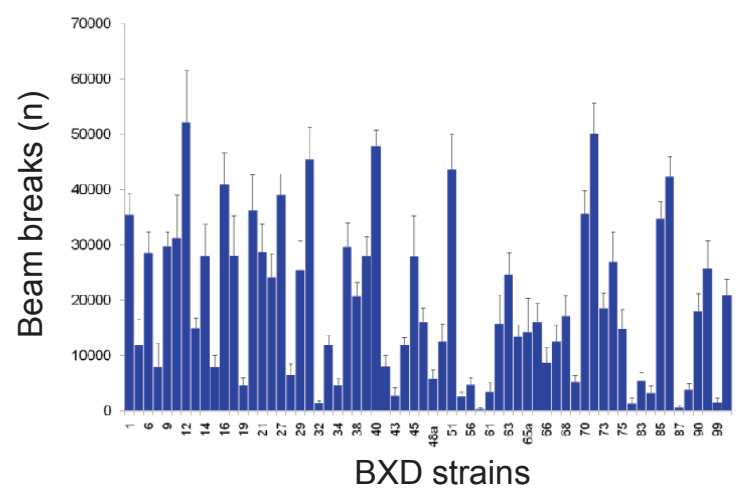

B

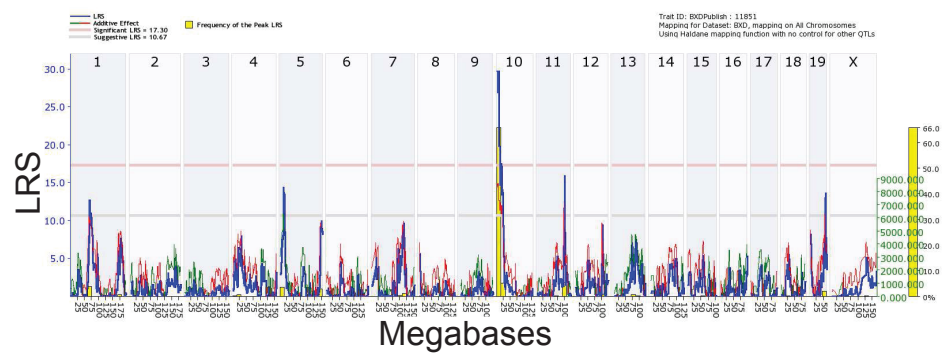

C

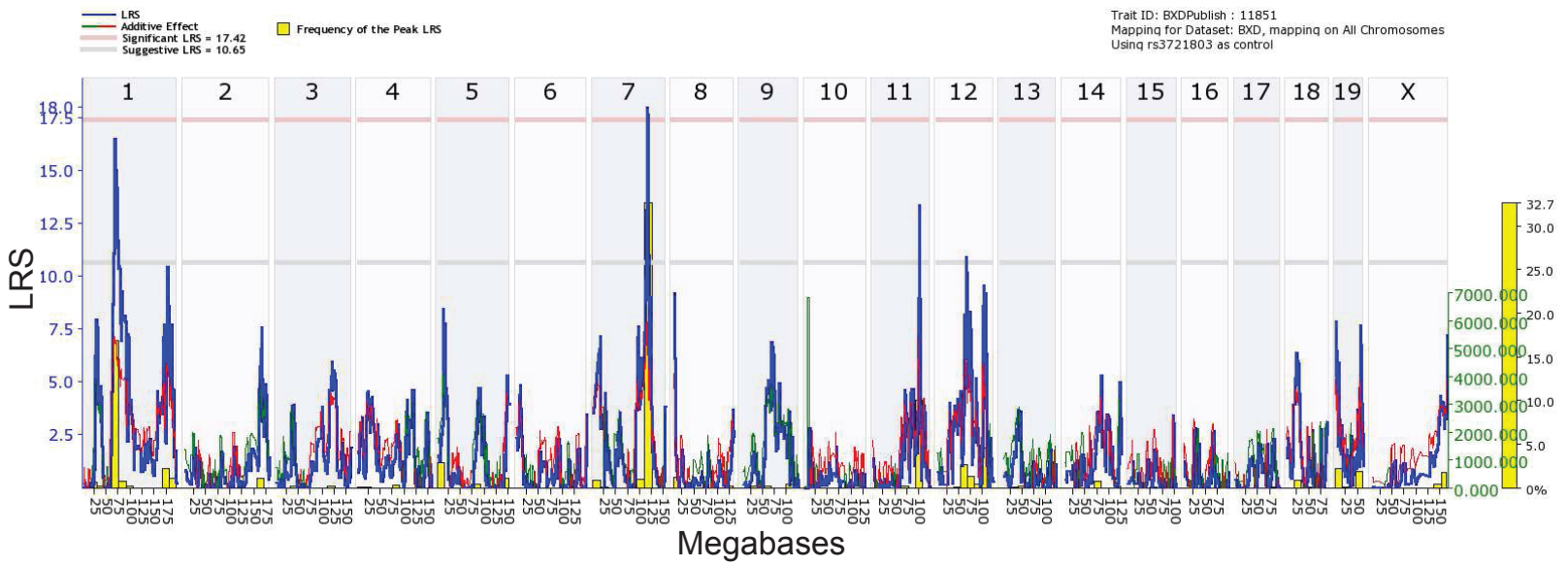

Figure 1. (A) Trait data for locomotion (distance traveled) for 64 BXD strains post morphine injection (Trait id 11851). (B) Whole genome scan showing a robust QTL on Chromosome 10 (Trait id 11851, SNP rs372180). The x-axis represents chromosome number and megabase position and the $y$-axis represents the likelihood ratio statistic (LRS) of linkage. Blue lines indicate LRS across the genome. The pink and gray horizontal lines are approximate threshold values which are used to assess whether a peak is significant $(P<0.05)$ or suggestive $(P<0.63)$, respectively. Red and green lines represent the additive genetic contribution: red lines indicate negative values (C57BL/6J alleles increasing trait values) and green lines indicate positive values (DBA/2J alleles increasing trait values). Gray lines are shown when the parental strain is unknown. The yellow bars represent the relative frequency of peak LRS at a given location from 2000 bootstrap resamples (C) Composite interval mapping of locomotion (Trait id 11851) after correcting for the peak on Chromosome 10 reveals a significant QTL on Chromosome 7.

\section{Conclusions}

Genetic analysis of the BXD RIS resulted in the detection of an additional locus for morphine induced locomotor activity and rearing on Chromosome 7 which may be associated with activation of the reward system pathway in response to morphine treatment. Whether this effect is opioid-specific or also occurs with other classes of drugs is not yet clear. Alternatively, this QTL may also be related to general locomotor activity or nociception, a central nervous system response to potentially harmful stimuli. The best gene candidates within the QTL interval, besides the positional candidates Syt9 and Ppfibp2, are Calca and Cckbr (sensory perception of pain) and $P d e 3 b$ (morphine addiction).

\section{Data availability}

All data are available in GeneNetwork (www.genenetwork.org; see supplementary worksheet 1 for trait-ids and descriptions). Trait 
IDs: Locomotion: 11843, 11833, 11844, 11834, 11845, 11835, 11846, 11847, 11851, 11852, 11836, 11837, 11838, Rearing: 11884, 11885, 11886, 11887, 11888, 11878, 11854.

Data are also available in the Supplementary material.

Author contributions

WEC assisted in interpreting the results and writing the manuscript; ED performed the functional annotation analysis; EJC provided the original data and assisted with interpreting the results and writing the manuscript; AD conceived the study, supervised the analyses, and wrote the manuscript. All authors approved the final submitted draft.

\section{Competing interests}

No competing interests were disclosed.

\section{Grant information}

BioScience Project is a 501(c)(3) research and teaching organization. EJC was supported by grants from NIAAA (AA018776) for GeneWeaver and NIDA (DA037927) for addiction genetics.

The funders had no role in study design, data collection and analysis, decision to publish, or preparation of the manuscript.

\section{Supplementary material}

GeneNetwork traits used in the QTL analysis.

Click here to access the data.

List of genes within the Chromosome 7 interval.

Click here to access the data.

Adinoff B: Neurobiologic processes in drug reward and addiction. Harv Rev Psychiatry. 2004; 12(6): 305-320.

PubMed Abstract | Publisher Full Text | Free Full Text

Bergeson SE, Helms ML, O'Toole LA, et al:: Quantitative trait loci influencing morphine antinociception in four mapping populations. Mamm Genome. 2001; 12(7): 546-553.

PubMed Abstract | Publisher Full Text

Crabbe JC, Phillips TJ, Gallaher EJ, et al:: Common genetic determinants of the ataxic and hypothermic effects of ethanol in BXD/Ty recombinant inbred mice: genetic correlations and quantitative trait loci. J Pharmacol Exp Ther. 1996; 277(2): 624-632.

PubMed Abstract

Dickson PE, Miller MM, Calton MA, et al.: Systems genetics of intravenous cocaine self-administration in the BXD recombinant inbred mouse panel. Psychopharmacology (Berl). 2016; 233(4): 701-714.

PubMed Abstract | Publisher Full Text | Free Full Text

Doyle GA, Schwebel CL, Ruiz SE, et al.: Analysis of candidate genes for morphine preference quantitative trait locus Mop2. Neuroscience. 2014; 277: 403-416.

PubMed Abstract | Publisher Full Text | Free Full Text

Gardner EL: Addiction and brain reward and antireward pathways. Adv Psychosom Med. 2011; 30: 22-60.

PubMed Abstract | Publisher Full Text | Free Full Text

Gill KJ, Boyle AE: Genetic basis for the psychostimulant effects of nicotine: a quantitative trait locus analysis in $\mathrm{AcB} / \mathrm{BCA}$ recombinant congenic mice.

Genes Brain Behav. 2005; 4(7): 401-411.

PubMed Abstract | Publisher Full Text

Gora-Maslak G, McClearn GE, Crabbe JC, et al:: Use of recombinant inbred strains to identify quantitative trait loci in psychopharmacology. Psychopharmacology (Berl). 1991; 104(4): 413-424.

PubMed Abstract | Publisher Full Text

Keane TM, Goodstadt L, Danecek P, et al:: Mouse genomic variation and its effect on phenotypes and gene regulation. Nature. 2011; 477(7364): 289-294. PubMed Abstract | Publisher Full Text | Free Full Text

Korostynski M, Kaminska-Chowaniec D, Piechota M, et al:: Gene expression profiling in the striatum of inbred mouse strains with distinct opioid-related phenotypes. BMC Genomics. 2006; 7: 146.

PubMed Abstract | Publisher Full Text | Free Full Text

Mistry CJ, Bawor M, Desai D, et al:: Genetics of Opioid Dependence: A Review of the Genetic Contribution to Opioid Dependence. Curr Psychiatry Rev. 2014; 10(2): 156-167.

PubMed Abstract | Publisher Full Text | Free Full Text

NCBI: PPFIBP2 PPFIA binding protein 2 [ Homo sapiens (human)]. Gene. National Center for Biotechnology Information, 2016a.

Reference Source

NCBI: Syt9 synaptotagmin IX [ Mus musculus (house mouse)]. Gene. Nationa Center for Biotechnology Information, 2016b.

Reference Source

Peirce JL, Lu L, Gu J, et al.: A new set of BXD recombinant inbred lines from advanced intercross populations in mice. BMC Genet. 2004; 5: 7 . PubMed Abstract | Publisher Full Text | Free Full Text

Philip VM, Duvvuru S, Gomero B, et al:: High-throughput behavioral phenotyping in the expanded panel of BXD recombinant inbred strains. Genes Brain Behav 2010; 9(2): 129-159.

PubMed Abstract | Publisher Full Text | Free Full Text

Plomin R, McClearn GE, Gora-Maslak G, et al.: Use of recombinant inbred strains to detect quantitative trait loci associated with behavior. Behav Genet. 1991; 21(2): 99-116.

PubMed Abstract | Publisher Full Text

Spence J, Liang T, Foroud T, et al:: Expression profiling and QTL analysis: a powerful complementary strategy in drug abuse research. Addict Biol. 2005 10(1): 47-51.

PubMed Abstract | Publisher Full Text | Free Full Text 


\section{Open Peer Review}

\section{Current Peer Review Status:}

\section{Version 1}

Reviewer Report 28 September 2016

https://doi.org/10.5256/f1000research.10214.r16660

(C) 2016 Gerlai R. This is an open access peer review report distributed under the terms of the Creative Commons Attribution License, which permits unrestricted use, distribution, and reproduction in any medium, provided the original work is properly cited.

\section{Robert Gerlai}

Department of Psychology, University of Toronto, Mississauga, ON, Canada

I have only minor comments, listed below.

1. "In the present study we reanalyzed data from high throughput behavioral phenotyping of BXD RIS in the presence of morphine (Philip et al., 2010)." Although it is clear what the authors are trying to say, strictly speaking this sentence implies that the authors had morphine present (on their desks? Or in their bloodstream??) when they were analyzing the data. Please make the sentence less ambiguous.

2. "Strain mean scores were Winsorized when statistical outliers were present". Please elaborate on this and/or cite references to support the decision to modify as opposed to exclude data.

3. "We remapped these data for each time point using composite interval mapping to identify QTLs potentially masked by this large QTL." Please clarify what "time point" refers to here.

4. "protein coding genes" this is a redundant expression. Please use either "protein coding sequences" or "genes".

In the discussion, perhaps a few words could be mentioned about why in general reanalysis of prior phenotyping data may yield useful new pieces of information about QTLs..

Competing Interests: No competing interests were disclosed.

I confirm that I have read this submission and believe that I have an appropriate level of expertise to confirm that it is of an acceptable scientific standard.

Reviewer Report 14 September 2016

https://doi.org/10.5256/f1000research.10214.r16166 
(c) 2016 Parker C. This is an open access peer review report distributed under the terms of the Creative Commons Attribution License, which permits unrestricted use, distribution, and reproduction in any medium, provided the original work is properly cited.

\section{Clarissa Parker}

Department of Psychology and Program in Neuroscience, Middlebury College, Middlebury, VT, USA

The manuscript from Crusio et al. describes the use of GeneNetwork to identify QTLs associated with morphine response in a genetic reference mouse population. The authors highlight many strengths afforded by both GeneNetwork and the BXD recombinant inbred mice. Specifically, they used composite interval mapping to reanalyze publicly available phenotypic and genotypic data in the BXDs to identify a QTL on chromosome 7 that had been masked by a major QTL on chromosome 10. Next, they employed a bioinformatics approach to prioritize among candidate genes within the QTL interval. This resulted in the identification of promising candidate genes that may be associated with drug-abuse phenotypes.

One step that would strengthen the manuscript would be to use QTLminer in GeneNetwork to examine cis-regulation of the genes located within the QTL support interval (or even just the most promising candidate genes) and to see if any of those genes were expression QTLs in BXD mice.

In addition, the authors raise an interesting question when they ask whether the chromosome 7 QTL is opioid-specific, or if it also occurs with other classes of drugs. They could use GeneNetwork to search for genetic correlations between the expression levels of their top candidate genes and drug-related traits.

Minor Points:

On the GeneNetwork website, Trait ID 11851 is defined as the number of beam breaks after morphine injection, but is described as "distance traveled" and "locomotion" in the Figure 1 legend of the manuscript.

Competing Interests: No competing interests were disclosed.

\section{I confirm that I have read this submission and believe that I have an appropriate level of expertise to confirm that it is of an acceptable scientific standard.}

Author Response 19 Oct 2016

Anna Delprato, BioScience Project, Wakefield, USA

Reviewer comment: "One step that would strengthen the manuscript would be to use QTLminer in GeneNetwork to examine cis-regulation of the genes located within the QTL support interval (or even just the most promising candidate genes) and to see if any of those genes were expression QTLs in BXD mice."

Of the candidate genes there is a marginally significant cis-eQTL for Syt9 ( LRS =18) but this is with one probe and in the striatum dataset only. There are no cis-eQTL for the other gene 
candidates.

Reviewer comment: "In addition, the authors raise an interesting question when they ask whether the chromosome 7 QTL is opioid-specific, or if it also occurs with other classes of drugs. They could use GeneNetwork to search for genetic correlations between the expression levels of their top candidate genes and drug-related traits."

Correlation analyses do not rule out or support association with other drugs. The few significant correlations that we found were based on less than 10 common strains.

Competing Interests: No competing interests were disclosed.

The benefits of publishing with F1000Research:

- Your article is published within days, with no editorial bias

- You can publish traditional articles, null/negative results, case reports, data notes and more

- The peer review process is transparent and collaborative

- Your article is indexed in PubMed after passing peer review

- Dedicated customer support at every stage

For pre-submission enquiries, contact research@f1000.com 